\title{
Removal of arsenic from groundwater by electro-ultrafiltration
}

\author{
Lin-Han Chiang Hsieh ${ }^{\mathrm{a}}$, Yu-Hsiang Weng ${ }^{\mathrm{b}}$, \\ Chin-Pao Huang ${ }^{\mathrm{c}}$, Kung-Cheh $\mathrm{Li}^{\mathrm{d}}{ }^{*}$ \\ ${ }^{a}$ CECI Engineering Consultants, Inc., 28 F., No. 185, Sec. 2, Sinhai Rd., Taipei, Taiwan 106, ROC \\ ${ }^{b}$ Institute of Nuclear Energy Research, Atomic Energy Council, Executive Yuan, Taoyuan, Taiwan 325, ROC \\ ${ }^{c}$ Department of Civil and Environmental Engineering, University of Delaware, Newark, DE 19716, USA \\ ${ }^{d}$ Graduate Institute of Environmental Engineering, National Taiwan University, Taipei, Taiwan 106, ROC \\ Tel.+886(2) 23698112; Fax +886(2) 23638173; email: kcli@ntu.edu.tw
}

Received 8 August 2007; accepted revised 28 September 2007

\begin{abstract}
The objective of this study was to examine the removal of arsenic from groundwater by a laboratory scale electro-ultrafiltration (EUF) system. Two groundwater samples taken from I-Ian County located in the northeastern part of Taiwan were studied. These well waters were selected based on their As(III) and As(V) contents; the $\mathrm{As}(\mathrm{III})$ to $\mathrm{As}(\mathrm{V})$ ratios of the well water were 1.8 and 0.4 for Well-\#1 and Well-\#2, respectively. In the absence of electrical voltage, the total arsenic removal efficiencies were $1 \%$ and $14 \%$ for Well-\#1 and Well-\#2 samples, respectively, using 100-kDa membranes. The higher As removal efficiency of Well-\#2 than that of Well-\#1 sample might be attributed to different charge characteristics of As(V) and As(III). Upon the application of an electrical voltage of $25 \mathrm{~V}$ to the ultrafiltration (UF) system, it was able to reduce the total arsenic concentrations in both groundwater samples by over $79 \%$. The result suggested the possible association between As(III) species and dissolved organic matter which enhanced the As removal.
\end{abstract}

Keywords: Electro-ultrafiltration (EUF); As(III); As(V)

\section{Introduction}

It has been reported that the presence of arsenic in surface and ground water is a public

*Corresponding author.

Presented at the Fourth Conference of Aseanian Membrane Society (AMS 4), 16-18 August 2007, Taipei, Taiwan. health issue. Consuming arsenic-containing water would have severe adverse effect on health, both acute and chronic. As a result, many countries, including Taiwan and the U.S., have lowered the arsenic maximum contamination 
level from 50 to $10 \mu \mathrm{g} / \mathrm{L}$ in order to minimize the risk of arsenic related illness [1,2].

Membrane separation is believed to be one of the most effective alternatives for the treatment of arsenic-containing water [3,4]. The molecular weights of arsenite, $\mathrm{H}_{3} \mathrm{AsO}_{3}$, and arsenate, $\mathrm{H}_{3} \mathrm{AsO}_{4}$, are 126 and $142 \mathrm{~g} /$ mole respectively, which implies that porous membranes, such as microfiltration (MF) and ultrafiltration (UF) alone, are not able to separate them directly [5]. In fact, nonporous membranes, such as nanofiltration (NF) and reverse osmosis (RO) are needed to achieve high separation efficiency. Previous studies have showed that charge effect can be an important factor governing arsenic exclusion, particularly for $\mathrm{As}(\mathrm{V})$ removal by membrane processes [6-10]. In neutral $\mathrm{pH}, \mathrm{As}(\mathrm{V})$ is anionic but As(III) is neutral species. Therefore, As(V) could be excluded partially due to charge effect, i.e., Donnan effect. For example, Seidel et al. [7] showed that the removal of $\mathrm{As}(\mathrm{V})$ was $60-90 \%$ whereas that of As(III) was only 5-28\% using a loose NF membrane. Regarding UF membrane, the arsenic rejection is insignificant because the pore size of UF is too large to exclude arsenic. Typical $\mathrm{As}(\mathrm{V})$ and $\mathrm{As}(\mathrm{III})$ rejections by UF are $40 \%$ and $5 \%$, respectively $[10,11]$.

In order to enhance the performance of UF, an electric field is applied across the membrane as to attract the charge species. This is the electrofiltration process. Much has been reported that electrofiltration can reduce fouling, increase rejection and at the same time purify water $[10,12]$. In a previous study, we have shown that the removal of $\mathrm{As}(\mathrm{V})$ in the presence of humic substances from synthetic water could be achieved by electro-ultrafiltration (EUF) with a $100-\mathrm{kDa}$ membrane at neural $\mathrm{pH}$ [10]. Additionally, when $\mathrm{pH}$ was raised to 10 , it was able to increase As(III) removal from 14 to $76 \%$ by EUF. However, it is not clear whether EUF is effective to treat arsenic in natural groundwater when both $\mathrm{As}(\mathrm{V})$ and $\mathrm{As}(\mathrm{III})$ are present concurrently.
In this study, groundwater samples with high arsenic content were taken from northeastern Taiwan. EUF experiments were conducted to evaluate the effect of electric voltage on arsenic rejection and flux. Finally, a preliminary economic analysis of the treatment process was made.

\section{Materials and methods}

\subsection{Water sampling}

The groundwater sampling sites are located at I-Lan county, northeastern Taiwan, Republic of China [13]. These two well waters have been reported to contain high arsenic content and therefore they are currently banned as drinking water sources. Furthermore, based on a previous survey [14], these two wells have different As(III) to $\mathrm{As}(\mathrm{V})$ concentration ratios and were therefore chosen for this study. The groundwater samples were drawn by pumping. A total of 20 liter of groundwater was collected from each well. The collected water samples were transported to the laboratory, filtered with a $0.45 \mu \mathrm{m}$ membrane to remove particulates and bacteria and then stored at $4^{\circ} \mathrm{C}$ until EUF studies. Each EUF experiment used five liters of water.

\subsection{Membrane and module}

UF membranes with molecular weight of 100-kDa (purchased from Osmonic) were used in this study. These polyacrylonitrile (PAN) membranes are hydrophilic with a contact angle of $4^{\circ}$ (provided by the manufacturer). The filtration area is $14.7 \mathrm{~cm}^{2}$. A piece of membrane was cut and soaked in distilled water for one hour before experiment. The filtration module consists of two plastic plates, one silicon lining and two electrodes. The anode and cathode are made of platinum and titanium, respectively. The distance between the electrodes is about $4 \mathrm{~mm}$. The membrane is placed in between the electrodes. The detailed layout of this EUF cell has been reported previously [10]. 


\subsection{Filtration experiments}

Five liters of groundwater were used for each experiment. A power supply (Chroma, Model $6210 \mathrm{~K}-600$ ) was employed to provide electrical voltage across the membrane. A peristaltic pump conveyed solution into the EUF cell with an average crossflow velocity of $0.1 \mathrm{~m} / \mathrm{s}$. Pressure was maintained at $98 \mathrm{kPa}$ during the experiment. An electric balance (Satorius) was used to monitor the amount of permeate passing through the membrane. Data collected were fed into a computer equipped with data acquisition software. The experiments were operated at a total recycle mode, i.e., recycling both concentrate and permeate streams back to the feed tank except for the aliquots of sample taken for water quality analysis.

\subsection{Chemical analyses}

Total arsenic concentration was analyzed following procedures of Standard Methods using Perkin Elmer Analyst 800 [15]. As(V) was reduced to $\mathrm{As}(\mathrm{III})$ by adding concentrated $\mathrm{HCl}$ and $\mathrm{KI}(20 \% \mathrm{w} / \mathrm{v})$. After one hour of reaction, the arsine gas was generated by continuous addition of $\mathrm{NaBH}_{4}$. Absorbance of arsine at $193.7 \mathrm{~nm}$ was recorded as peak high.

Arsenic speciation was made by combining ion chromatography (Waters Model 600) and hydride generation Atomic Absorption Spectrometry (Perkin Elmer). Sample with a volume of $200 \mu \mathrm{L}$ sample was injected into a separation column (Phenomenx, Nucleosil 10SB 100A $4.6 \times 250 \mathrm{~mm})$. The arsenic species were eluted with mobile phase, a phosphate solution at $\mathrm{pH}$ 4.8. The flow rate was controlled at $1.5 \mathrm{~mL} / \mathrm{min}$.

DOC was analyzed using OI Analytical 1010. Measurement of $\mathrm{pH}$ was carried out with a Consort $\mathrm{C} 831 \mathrm{pH}$ meter. Conductivity was measured with a Suntex SC-120 conductivity meter.

\section{Results and discussion}

\subsection{Total arsenic and DOC removal efficiency}

Table 1 shows chemical characteristics of the two well water samples in I-lan County, Taiwan, Republic of China. Water temperature, $\mathrm{pH}$ and conductivity of Well-\#1 sample were similar to those of Well-\#2 except the As content. Typically, the total arsenic concentration of well water in I-lan County ranges from $<0.15 \mu \mathrm{g} / \mathrm{L}$ to $3.59 \mathrm{mg} / \mathrm{L}$ [16], showing a high degree of concentration variation of arsenic in this region. The results show that As(III) dominated the arsenic species in Well-\#1, whereas $\operatorname{As}(\mathrm{V})$ was the major As species in Well-\#2. This is consistent with a previous survey conducted in 1999 [14].

The rejection of total arsenic or DOC $\left(R_{f}\right)$ was calculated by Eq. (1) in which $C_{p}$ is the arsenic or DOC concentration in the permeate and $C_{0}$ is the initial arsenic or DOC concentration. Measurements followed the method described previously.

$R_{f}=\left(1-\frac{C_{p}}{C_{0}}\right) \times 100 \%$

Fig. 1 shows the total arsenic rejection in Well-\#1 and Well-\#2 samples with and without

Table 1

Characteristics of the well waters studied (I-Lan County, Taiwan, ROC)

\begin{tabular}{lll}
\hline & Well-\#1 & Well-\#2 \\
\hline Temperature $\left({ }^{\circ} \mathrm{C}\right)$ & 24.0 & 24.1 \\
pH & 7.3 & 7.4 \\
Conductivity $(\mu \mathrm{S} / \mathrm{cm})$ & 480 & 500 \\
Total arsenic $(\mu \mathrm{g} / \mathrm{L})^{\mathrm{a}}$ & 49.4 & 304.6 \\
$\mathrm{As}(\mathrm{III})(\mu \mathrm{g} / \mathrm{L})^{\mathrm{b}}$ & 30.0 & 82.5 \\
$\mathrm{As}(\mathrm{V})(\mu \mathrm{g} / \mathrm{L})^{\mathrm{b}}$ & 16.4 & 203.7 \\
$\mathrm{As}(\mathrm{III}) / \mathrm{As}(\mathrm{V})^{\mathrm{b}}$ & 1.8 & 0.4 \\
$\mathrm{DOC}(\mathrm{mg} / \mathrm{L})$ & 0.7 & 1.5 \\
\hline
\end{tabular}

${ }^{\mathrm{a}}$ Total arsenic was analyzed by AA.

${ }^{\mathrm{b}}$ Arsenic speciation was analysis by HPLC-AA. 


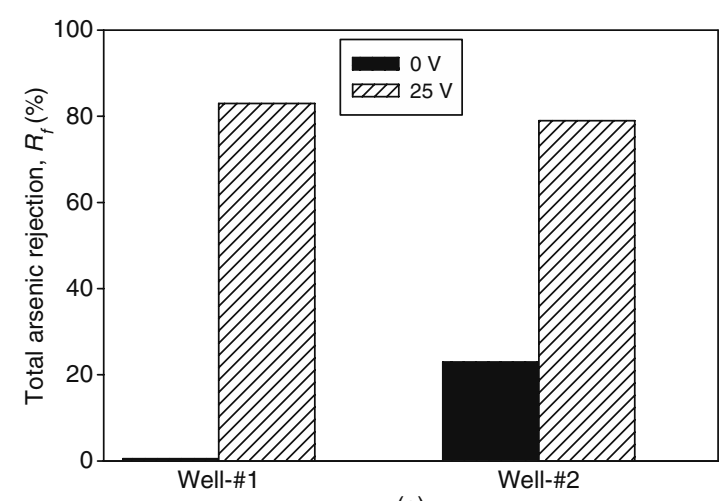

(a)

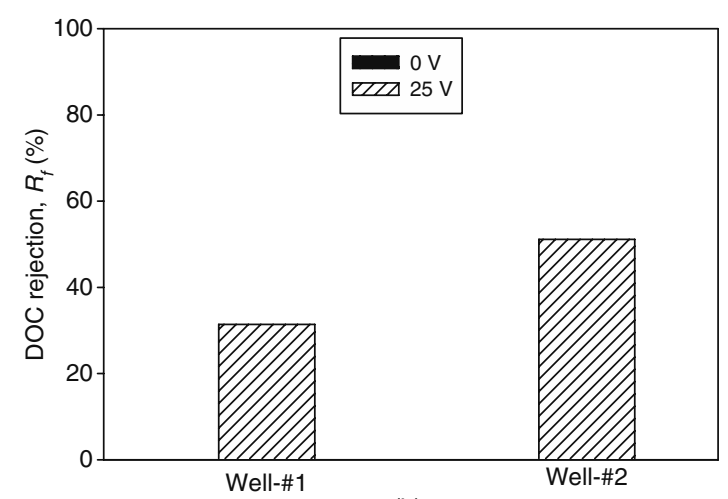

(b)

Fig. 1. Water quality improvement by EUF. (a) Total arsenic rejection; (b) DOC rejection.

voltages. Results clearly indicated that conventional UF removed less than $20 \%$ of arsenic from water. In addition, the total arsenic rejection for Well-\#2 sample was higher than that for Well-\#1 sample due to different arsenic composition. Since $\mathrm{As}(\mathrm{V})$ is negatively charged at neutral $\mathrm{pH}$, the additional As removal in Well-\#2 could be attributed partly due to the Donnan effect. This result is consistent with other studies which show that arsenic charge characteristic plays an important role to $\mathrm{As}(\mathrm{V})$ removal by membrane [4,6-11].

The current increased dramatically as voltage was increased. Therefore, in order to reduce the joule heating and the hydrolysis rate of the water, voltage was raised to $25 \mathrm{~V}$ only. It is surprising that total arsenic rejection was increased to more than $79 \%$ for both samples after applying $25 \mathrm{v}$. Furthermore, Fig. 1 shows that the DOC rejection was raised by more than $30 \%$ in the presence of an electric voltage of $25 \mathrm{v}$. According to our previous investigation on the EUF treatment of synthetic arsenic-containing water, the $\mathrm{As}(\mathrm{V})$ rejection was ca. 90\% whereas As(III) was ca. $10 \%$ only without $\mathrm{pH}$ adjustment at an initial As concentration of $\sim 30 \mu \mathrm{g} / \mathrm{L}$ [10]. To the best of our knowledge, there is no existing data dealing with the removal of As by EUF other than our previous study. Furthermore, it is essential to know if results obtained from laboratory study using synthetic water can be applied to treatment systems involving natural water. Therefore the result from synthetic water study was used as a first attempt to estimate the overall removal efficiency in natural groundwater. Based on results of synthetic water study, the arsenic rejections should be $38 \%$ for Well-\#1 and 67\% for Well-\#2 samples. However, the predicted removal efficiency was significantly smaller than the $79 \%$ measured for both well waters in this study (Fig. 1). Arsenic existing in natural groundwater may not behave the same as that in synthesis water. Specifically, other chemical components in the groundwater may interfere with As removal. As a matter of fact, other researchers have reported the formation of colloidal arsenic in surface and ground waters $[11,17]$. Our results suggest that As(III) might be associated with As(V) or dissolved organic matter which were attracted in the electric field. In addition, electrochemical reactions that reduce arsenic to arsine might occur in the EUF cell. It has been shown that the reduction of arsenic to arsine can take place in high ionic strength environment [18].

Moreover, the initial arsenic concentration can influence the arsenic removal efficiency also. Seidel et al. [7] reported that $\mathrm{As}(\mathrm{V})$ removal increased from 60 to $90 \%$ as the initial concentration increased from 10 to $316 \mu \mathrm{g} / \mathrm{L}$ using NF treatment. However, As(III) removal decreased as the initial arsenic content increased. Since the 
well water samples contained higher arsenic concentration in comparison to our previous study [10], the initial As concentration effect was applicable to Well-\#2 but not Well-\#1 sample. Thus, it seems that the increase in As rejection for Well-\#1 water predicted from the results obtained in synthetic water study was mainly due to the presence of arsenic-organic. It has been shown that As has high affinity to some organic/inorganic colloids [19]. As a consequence, the electrophoretic force could mitigate the movement of the negatively charged pollutants and thus increase the arsenic as well as DOC rejections.

\subsection{Flux and filtration resistance}

Fig. 2 shows the relative flux of groundwater over time. The relative flux is defined as the ratio of flux during EUF to Mili-Q water flow rate during flushing the membrane before experiment. The filtration resistance was calculated by the Darcy's law, i.e., in Eq. (2).

$$
J=\frac{\Delta P}{\mu R_{f}}
$$

In this equation, $J$ is flux $(\mathrm{m} / \mathrm{s}), \Delta P$ is applied pressure $(\mathrm{Pa}), \mu$ is viscosity $\left(\mathrm{N} \mathrm{s} / \mathrm{m}^{2}\right)$ and $R_{f}$ is

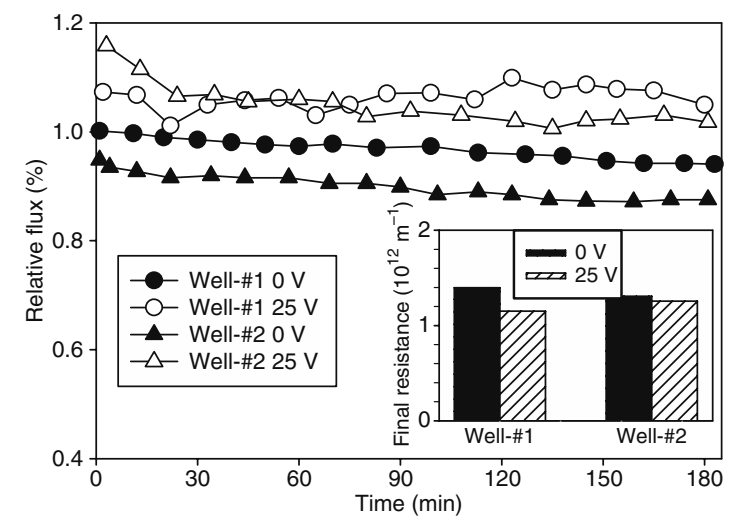

Fig. 2. Relative flux of groundwater samples over time. the filtration resistance $\left(\mathrm{m}^{-1}\right)$. The averaged flux of Mili-Q water was $7.96 \times 10^{-5} \mathrm{~m} / \mathrm{s}$ (or $286 \mathrm{~L} / \mathrm{m}^{2} \mathrm{~h}$ ) which corresponds to a filtration resistance of $1.23 \times 10^{12} \mathrm{~m}^{-1}$. Without applying the voltage, the flux declined to 94 and $88 \%$ of its Mili-Q water flux for Well-\#1 and Well-\#2 samples, respectively. A lower relative flux for Well-\#2 sample than for Well-\#1 sample was attributed to the presence of DOC at different concentrations in the well waters. It is well known that the higher DOC concentration, the higher is the flux decline.

During EUF treatment of groundwater with an applying voltage of $25 \mathrm{~V}$, the relative fluxes were greater than one. Obviously, this is indicative of significant electro-osmosis effect in response to electric field. The initial incremental flux was $7 \%$ for Well-\#1 water and $16 \%$ for Well-\#2 water when compared to the Mili-Q water flux. Other researchers also reported similar improvement in flux during EUF treatment of synthetic surface water $[10,20]$. It is noted that membrane property and solution environment can affect the magnitude of electroosmosis. The presence of electric-active ions in solution can bring about higher initial electroosmosis for Well-\#2 water. Chuang et al. [21] reported that electrolyte concentration can also affect the electroosmotic flux. However, the final relative flux of Well-\#2 water was lower than that of Well-\#1 water. It is clear that the DOC content in Well-\#2 was higher than that in Well-\#1 water which might bring about lower relative flux in Well-\#2 water over time. Furthermore, the filtration resistance decreased upon the application of electric voltage. The filtration resistance of the well waters at $25 \mathrm{~V}$ was comparable to that of the Milli-Q water. However, there was a $10 \%$ increase in filtration resistance of the well water in the absence of the assisted electric voltage. Park [22] and Weng et al. [10,12] have reported the reduction of filtration resistance previously in related studies. 
Table 2

Estimated electricity consumption of the EUF process

\begin{tabular}{lllll}
\hline & \multicolumn{2}{l}{ Well-\#1 } & \multicolumn{2}{l}{ Well-\#2 } \\
\hline Voltage $(\mathrm{V})$ & 0 & 25 & 0 & 25 \\
Current $(\mathrm{mA})$ & 0 & 70 & 0 & 76 \\
Volume $(\mathrm{L})$ & 1.15 & 1.39 & 1.23 & 1.29 \\
$E_{\text {ele }}\left(\mathrm{kW}-\mathrm{h} / \mathrm{m}^{3}\right)$ & - & 3.78 & - & 4.43 \\
$E_{\text {pump }}\left(\mathrm{kW}-\mathrm{h} / \mathrm{m}^{3}\right)$ & 195 & 162 & 183 & 175 \\
$E_{\text {total }}\left(\mathrm{kW}-\mathrm{h} / \mathrm{m}^{3}\right)$ & 195 & 166 & 183 & 179 \\
\hline
\end{tabular}

\subsection{Evaluation of electricity cost}

Table 2 lists the estimated energy consumption for the EUF module. The calculation included the electricity cost only, expressed in terms of electric voltage consumption per unit volume of water $\left(E_{\text {ele }}\right)$ and pump consumption per unit volume of water $\left(E_{\text {pump }}\right)$. The results indicate that the total energy consumption per unit volume of water $\left(E_{\text {total }}\right)$ decreased upon the application of electric voltage. This is expected as the electro-osmotic flow generated from the applied electric potential was parallel to that of the transmembrane gradient.

Furthermore, electrophoresis effect can repel foulants away from the membrane surface and therefore reduce the flux decline. As a result, the energy consumption during EUF was reduced in comparison to that in the absence of electric potential. It should be noted that the $E_{\text {total }}$ value obtained in this study was much higher than that reported by Weigert et al. [23] who studied the electro-microfiltration (EMF) systems using a much larger membrane area than ours, i.e., 900 versus $15 \mathrm{~cm}^{2}$. In this study, the energy consumption without considering pumping was $\sim 4 \mathrm{~kW}-\mathrm{h} / \mathrm{m}^{3}$ which is comparable to that reported by Bowen et al. [24] who studied the membrane fouling by Baker's yeast and titanium dioxide using pulsed electric mode EMF. They reported an energy consumption excluding pumping of $0.036 \sim 6.9 \mathrm{~kW}-\mathrm{h} / \mathrm{m}^{3}$. Wakeman and Sabri [25] also studied the filtration of titanium dioxide using EMF and reported an energy consumption of $\sim 2.5 \mathrm{~kW}-\mathrm{h} / \mathrm{m}^{3}$ when excluding pumping.

\section{Conclusion}

Results demonstrated that EUF could remove arsenic from groundwater effectively. Arsenic concentration was reduced by more than $79 \%$ upon the application of an electric voltage of at $25 \mathrm{~V}$. This is a significant improvement over conventional UF treatment, i.e., without application of electric voltage, which only exhibited $<20 \%$ arsenic removal. The residual arsenic concentrations in permeate were 8.4 and $49 \mu \mathrm{g} / \mathrm{L}$ from initial arsenic concentration of 49 and $304 \mu \mathrm{g} / \mathrm{L}$ for Well-\#1 and Well-\#2 water samples, respectively. In addition, the presence of electric voltage brings about electro-osmosis which can enhance flux and reduce electrical cost and ultimately make the process more competitive than other conventional arsenic-removing technologies. Although the arsenic content in Well-\#2 permeate exceeded the common environmental regulation standard, it is possible to attain a better performance by further optimizing the operation conditions.

\section{Acknowledgements}

This work was partly supported by the National Science Council of the Republic of China. We are thankful to Yu-Hsuan Chen with Institute of Occupational Medicine and Industrial Hygiene College of Public Health (National Taiwan University) for conducting HPLC-AA analysis.

\section{References}

[1] EPA, USA, available: http://www.epa.gov/ogwdw/ standards.html.

[2] EPA, ROC, available: http://law.epa.gov.tw/en/ laws/water/drinking.html. 
[3] M. Bissen and F. Frimmel, Arsenic - a review. Part II: Oxidation of arsenic and its removal in water treatment, Acta Hydroch. Hydrob., 31 (2003) 97-107.

[4] M.C. Shih, An overview of arsenic removal by pressure-driven membrane processes, Desalination, 172 (2005) 85-97.

[5] M. Mulder, Basic principles of membrane technology, 2nd edn., Kluwer Academic Publishers, 1996.

[6] Y. Sato, M. Kang, T. Kamei and Y. Magara, Performance of nanofiltration for arsenic removal, Water Res., 36 (2002) 3371-3377.

[7] A. Seidel, J.J. Waypa and M. Elimelech, Role of charge (Donnan) exclusion in removal of arsenic from water by a negatively charged porous nanofiltration membrane, Environ. Eng. Sci., 18 (2001) 105-113.

[8] T. Urase, J. Oh and K. Yamamoto, Effect of $\mathrm{pH}$ on rejection of different species of arsenic by nanofiltration, Desalination, 117 (1998) 11-18.

[9] P. Brandhuber and G. Amy, Arsenic removal by a charged ultrafiltration membrane - influences of membrane operating conditions and water quality on arsenic rejection, Desalination, 140 (2001) 1-14.

[10] Y.H. Weng, L.-H. Chiang Hsieh, H.H. Lee, K.C. Li and C.P. Huang, Removal of arsenic and humic substances (HSs) by electro-ultrafiltration (EUF), J. Hazard. Mater., 122 (2005) 171-176.

[11] P. Brandhuber and G. Amy, Alternative methods for membrane filtration of arsenic from drinking water, Desalination, 117 (1998) 1-10.

[12] Y.H. Weng, K.C. Li, L.-H. Chiang Hsieh and C.P. Huang, Removal of humic substances (HS) from water by electro-microfiltration (EMF), Water Res., 40 (2006) 1783-1794.

[13] L.-H. Chiang Hsieh, Electrically assisted ultrafiltration of water containing arsenic and natural organic matter, 2003 Master dissertation, Graduate Institute of Environ. Eng., National Taiwan Univ., Taipei, Taiwan, ROC.

[14] ROC Environmental Protection Administration, A survey of simple methods to remove arsenic from groundwater, EPA-88-J1-02-03-403 (1999) 16-21.
[15] American Public Health Association, American Water Works Association \& Water Pollution Control Federation. Standard methods for the examination water and wastewater, 20th edn., Method 3314 Arsenic and Selenium by Hydride Generation/ Atomic Absorption Spectrometry, pp. 3-32-3-37,. APHA, Washington, DC, USA, 1998.

[16] C.Y. Yang, C.C. Chang, S.S. Tsai, H.Y. Chuang, C.K. Ho and T.N. Wu, Arsenic in drinking water and adverse pregnancy outcome in an arseniasisendemic area in northeastern Taiwan, Environ. Res., 91 (2003) 29-34.

[17] Y. Tanizaki, T. Shimokawa and M. Yamazaki, Physico-chemical speciation of trace elements in urban streams by size fractionation, Water Res., 26 (1992) 55-63.

[18] D. Bejan and N. Bunce, Electrochemical reduction of $\mathrm{As}(\mathrm{III})$ and $\mathrm{As}(\mathrm{V})$ in acidic and basic solutions, J. Appl. Electrochem., 33 (2003) 483-489.

[19] M. DeMarco, A. Sengupta and J. Greenleaf, Arsenic removal using a polymeric/inorganic hybrid sorbent, Water Res., 37 (2003) 164-176.

[20] Y.-H. Weng and K.-C. Li, Electrically enhanced crossflow ultrafiltration for treatment of water containing humic acid: a preliminary study, Adv. Asian Environ. Eng., 3 (2003) 60-66.

[21] C. Chuang, C. Fang and K. Tung, Electro-microfiltration of colloidal suspensions, Separ. Sci. Technol., 38 (2003) 797-816.

[22] Y.G. Park, Effect of hydraulic pressure and electric field on electro-microfiltration in the wine-brewery industry, Desalination, 191 (2006) 411-416.

[23] T. Weigert, J. Altmann and S. Ripperger, Crossflow electrofiltration in pilot scale, J. Membr. Sci., 159 (1999) 253-262.

[24] W.R. Bowen, R.S. Kingdon and H.A.M. Sabuni, Electrically enhanced separation processes - the basis of in situ intermittent electrolytic membrane cleaning (IIEMC) and in situ electrolytic membrane restoration (IEMR), J. Membr. Sci., 40 (1989) 219-229.

[25] R. J. Wakeman and M. N. Sabri, Utilizing pulsed electric-fields in cross-flow microfiltration of titania suspensions, Chem. Eng. Res. Des., 73 (1995) 455-463. 